\title{
Rupture of a subungual glomus tumor of the finger
}

Hui Lu ${ }^{1 *}$, Li Feng Chen ${ }^{3}$ and Qiang Chen ${ }^{2}$

\begin{abstract}
Background: Glomus tumor is a rare benign neoplasm, which most frequently occurs in the subungual regions of digits. Tumor rupture and infection occurred in one patient with a glomus tumor have never been reported.

Case presentation: We report a 59-year-old female presented to our hospital with a five-year history of progressively sharp pain and severe tenderness in the tip of her right middle finger. The treatment was surgical excision through a lateral incision accompanied with removal of the nail. After the surgery, the patient gained a functional recovery of her previously afflicted finger.

Conclusions: To the best of our knowledge, this is the first case of finger infection caused by a ruptured subungual glomus tumor. Patients and physicians should be aware of the properties of glomus tumor so that early diagnosis and treatment of subungual glomus tumor as well as avoidance of tumor rupture and infection can be achieved.
\end{abstract}

Keywords: Subungual glomus tumor, Tumor rupture, Finger infection

\section{Background}

Glomus tumor is a rare benign neoplasm that most frequently occurs in the glomus body in the subungual regions of digits. Glomus tumor represents less than $2 \%$ of all soft tissues tumors $[1,2]$. The clinical manifestations of glomus tumor were first described as excruciating pain out of proportion to size, localized tenderness, and cold sensitivity by Masson in 1924 [3]. The diagnosis of glomus tumor is made based on both the clinical history and examination. But it is generally difficult to diagnose glomus tumor because of its rarity. After glomus tumor is correctly diagnosed, surgical excision is the most effective treatment $[4,5]$. Here, we report a patient with a ruptured and infected subungual glomus tumor in the finger due to a variety of misdiagnoses that delayed the correct diagnosis and effective treatment. To our knowledge, no such case has previously been reported.

\section{Case presentation}

This is a case of a 59-year-old female presented to our hospital with a five-year history of progressively sharp pain and severe tenderness in the tip of her right middle finger. She had numerous visits to different hospitals in the past, with multiple different diagnoses including neuroma, neuritis, Raynaud's disease, and menopausal syndrome. She was treated with nonsteroidal anti-inflammatory drugs (NSAID), morphine, and anxiolytics, none of which achieved a response. She even was recommended to receive an amputation of the affected digit. The pain was worse at night or during the heavy physical activity. She was unable to sleep at night due to the worsening pain. Sometimes she forced herself to put finger under her body and sleep on the painful finger. She had no trauma history or prior surgery. Swelling and pain with limited motion were observed in the distal interphalangeal joint (DIP) of the affected

\footnotetext{
* Correspondence: huilu@zju.edu.cn

${ }^{1}$ Department of Hand Surgery, The First Affiliated Hospital, College of

Medicine, Zhejiang University, \#79 Qingchun Road, Hangzhou, Zhejiang

Province, People's Republic of China 310003

Full list of author information is available at the end of the article
}

(c) The Author(s). 2018 Open Access This article is distributed under the terms of the Creative Commons Attribution 4.0 International License (http://creativecommons.org/licenses/by/4.0/), which permits unrestricted use, distribution, and 
finger. The distal nail root appeared dense purple in color due to a long soak in the povidone lodine solution (Fig. 1). Partial necrosis of skin in the nail root was seen. The physical examination revealed the following findings: The distal and middle finger was red, hot, swollen and painful. There were erythema, edema and warmth of the skin in the middle finger. Positive Love's test, which identified the exact location of the tenderness by pressing with the head of a pin or paper clip. In this particular case, the Love's test was atypical. The whole finger was tenderness, and the radial subungual of middle finger was more painful. Positive Hildreth's test, which showed that pain subsided after a tourniquet was applied to the base of the finger. Positive cold sensitivity test, which demonstrated an increase of the localized pain when her middle finger was exposed to cold water, based mainly on the past medical history. Laboratory studies showed that the neutral granular cell count was elevated, but erythrocyte sedimentation rate (ESR) and highsensitivity C-reactive protein (CRP) were all within the normal ranges. Plain $\mathrm{X}$-ray films documented some concavity in the distal phalanx with soft tissue swelling (Fig. 2). Magnetic resonance imaging (MRI) revealed the bone cortex of distal phalanx in right middle finger was coarse, the boundary was unclear, soft tissue nearby was swollen. An approximately solid, well-delimited subungual nodule with hyperintense on T2-weighted image. Soft tissue of the distal middle finger was swollen with hyperintense on T2weighted image. (Fig. 3). The lateral, radial and dorsal incision was made according to the appearance of MRI and palpation [6]. We removed the

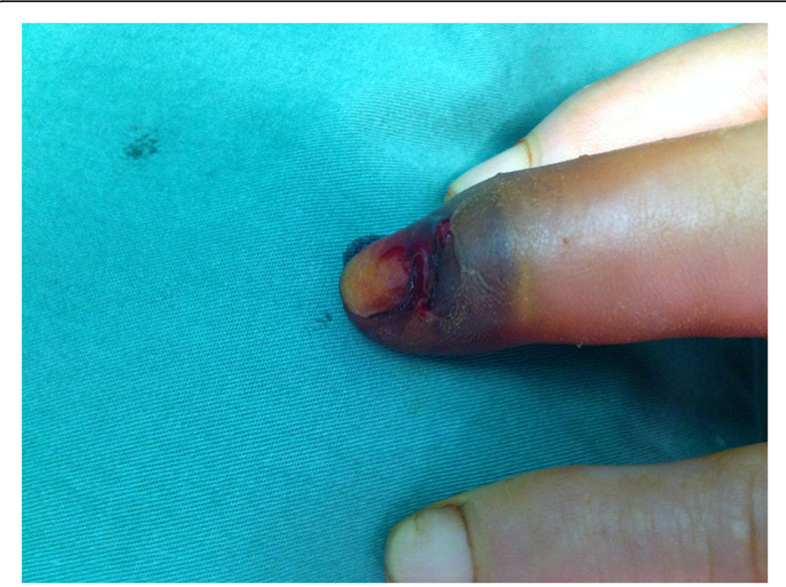

Fig. 1 Swelling, pain, and limited motion are observed in the DIP joint. The distal nail root appears dense purple in color

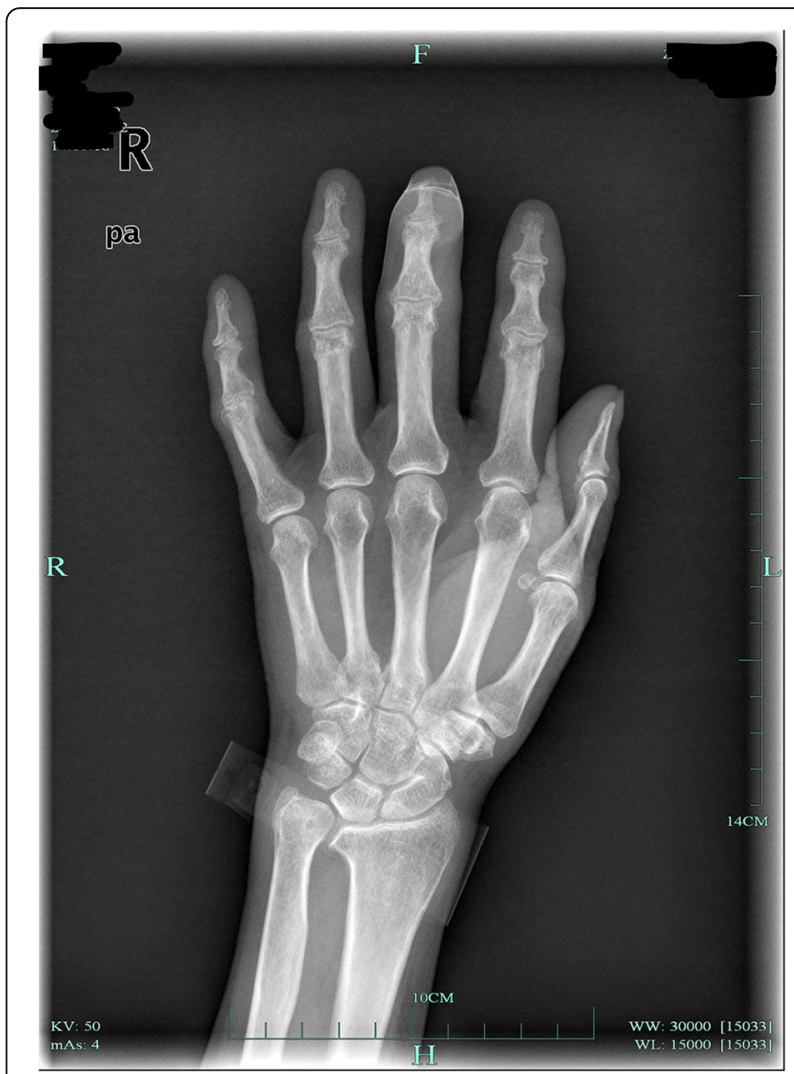

Fig. 2 Plain X-ray films document some concavity in the distal phalanx with soft tissue swelling

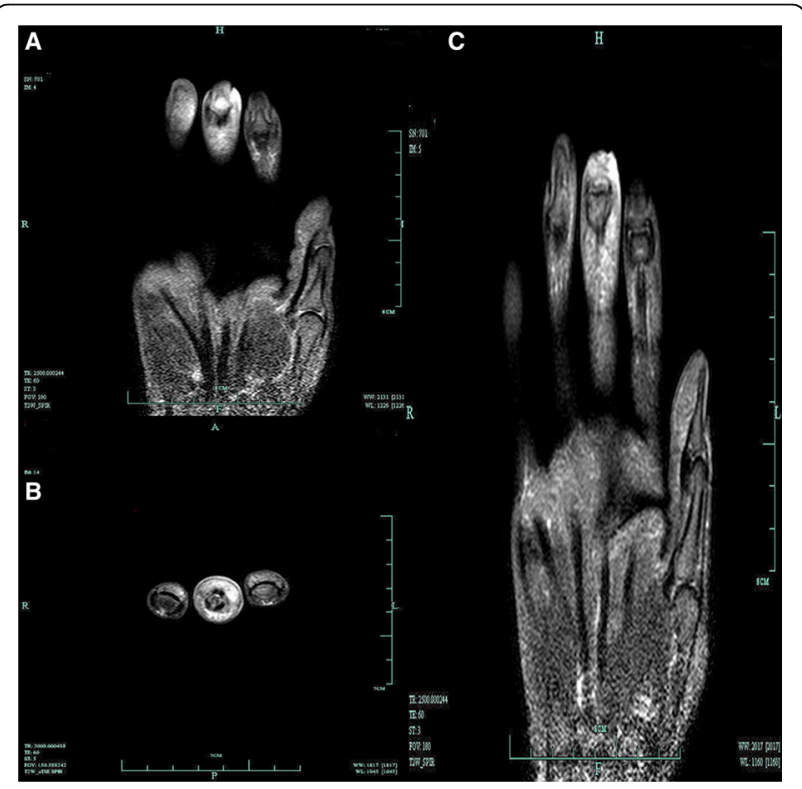

Fig. 3 Magnetic resonance imaging (MRI) reveals a subungual approximately solid, well-delimited nodule with hyperintense on the coronal T2-weighted image (a) and the axial T2-weighted image (b). Soft tissue of the distal middle finger is hyperintense on the coronal T2weighted image (c) 


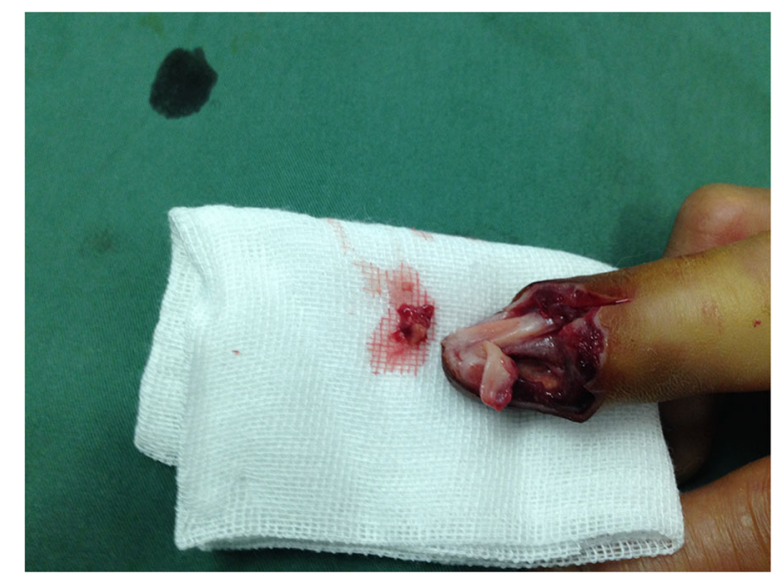

Fig. 4 Glomus tumor is ruptured under the nail bed

finger nail. The cuticle was partial necrosis. The nail bed and matrix were incised longitudinally, the phalangette was exposed. We found the ruptured glomus tumor, seropurulent pus and inflammatory granulation tissue and we did the debridement in the subungual cavity. The impression of distal phalanx was seen. The nail bed and cuticle were sutured, the wound was closed primarily. (Fig. 4).
Surgical procedure was carried out with surgical loupes. Patient who suspected glomus tumor, the clinical diagnosis can be confirmed by MRI and clinical examining (as Love's test, tourniquet test etc). In this atypical case, we hope to order a tissue biopsy to make a definitive diagnosis. We gave up the biopsy in consideration of pin-track infections. Pathologic findings showed a subungual glomus tumor with glomus cells and chronic inflammatory cell infiltrates. Immunohistochemistry results were SMA (+), desmin $(-)$,CD34 $(+)$,caldesmon $(+)$,vimentin $(+)$ (Fig. 5). Glomus cells are normally immunoreactive with SMA and vimentin. Then the endothelial markers such as CD31 will be helpful in distinguishing glomus tumor from hemangiomas that are lined with unique vascular endothelial cells.

After surgery, the patient was pain-free and she reported uninterrupted sleep for the first time in 5 years. She took $200 \mathrm{mg}$ of Celebrex, twice a day for 1 week. The patient received Cefuroxime (Glaxo Wellcome Operations, UK; $0.5 \mathrm{~g}$ twice a day) for 1 week after the surgery. She achieved a significant recovery and experienced no tumor recurrence in 3 years after surgery (Figs. 6, and 7). These study protocols were approved by the Medical Ethics Committee of the First Affiliated Hospital, College of Medicine, Zhejiang University.

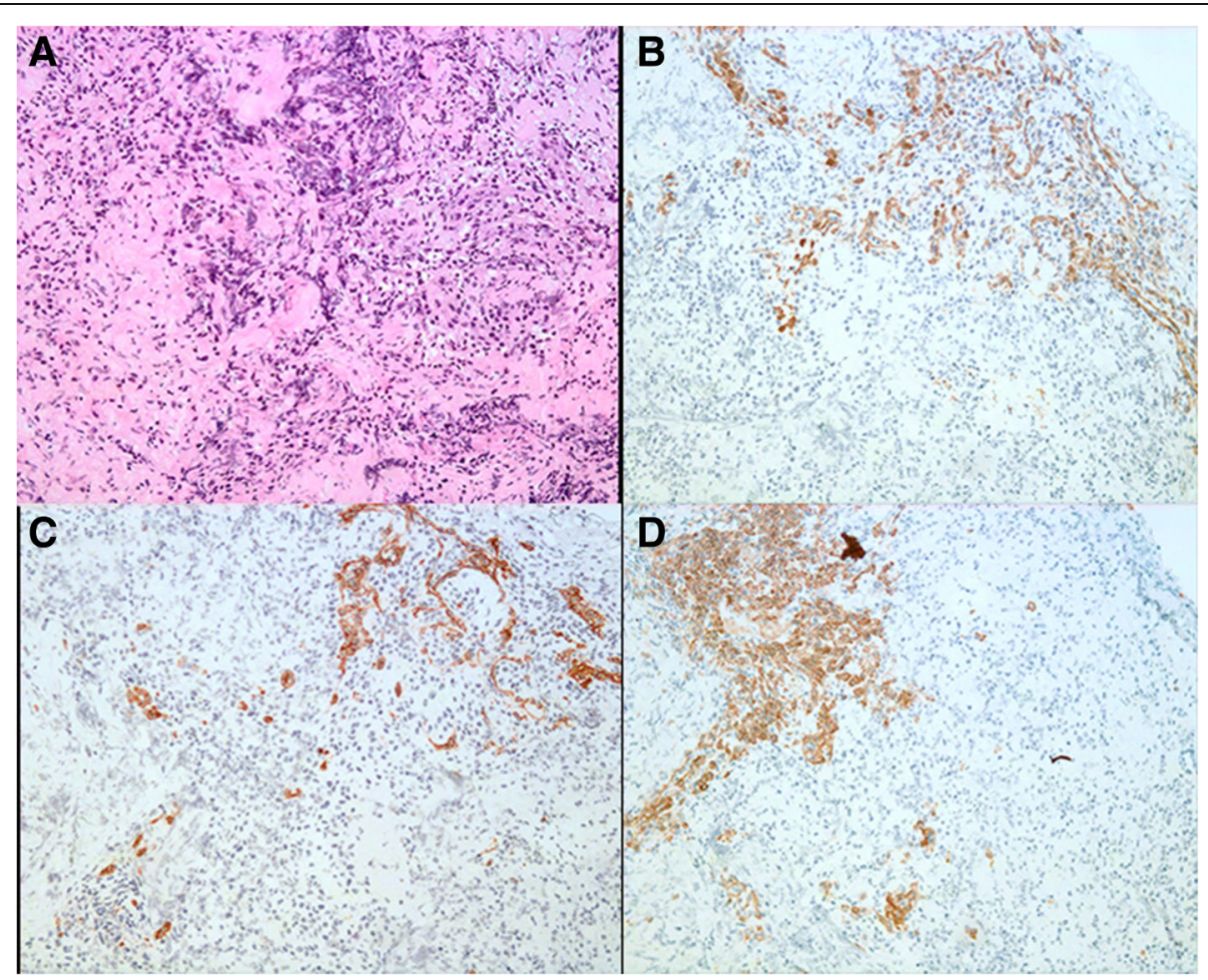

Fig. 5 Pathologic examination shows a subungual glomus tumor with chronic inflammatory cell infiltrates (a) (200X, HE). Immunohistochemistry shows SMA (+) (b), CD34 (+) (c), and Caldesmon (+) (d) 


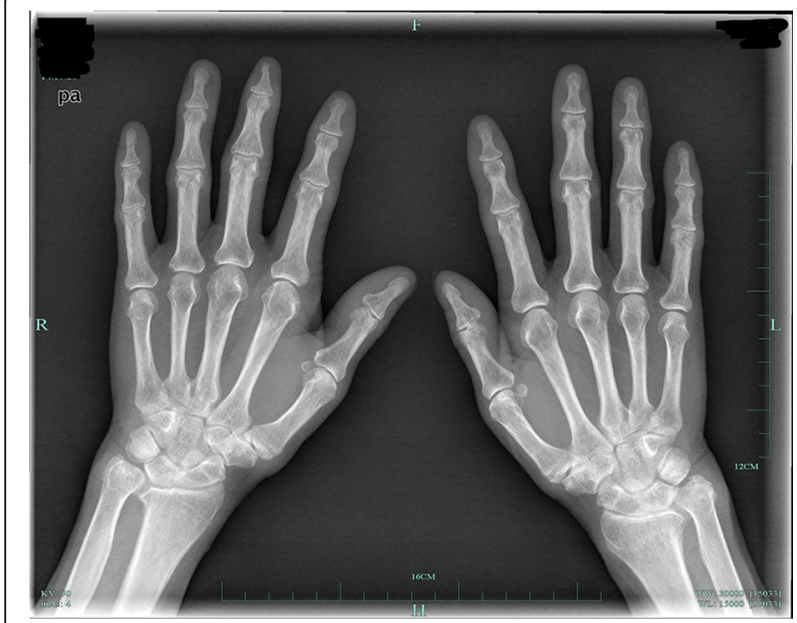

Fig. 6 Plain X-ray films document no tumor recurrence in three years after surgery

\section{Discussion}

In authors' experiences, physical examination and medical history may be informative enough for a correct diagnosis of a disease. However, increased awareness of a disease, especially a rare disease by both the patients and physicians are crucial for early diagnosis and treatment. Delay in the correct diagnosis for this patient presented here eventually led to the rupture and infection of this rare subungual glomus tumor.

Medical imaging can detect the lesion of glomus tumor and thus help arrive at the correct diagnosis. Ultrasound can detect the lesions, but it is so heavily dependent on the operator's expertise [7]. MRI is a better method for locating and displaying the tumor directly $[8,9]$, but sometimes it still fails to detect the lesions in some patients in our hospital.

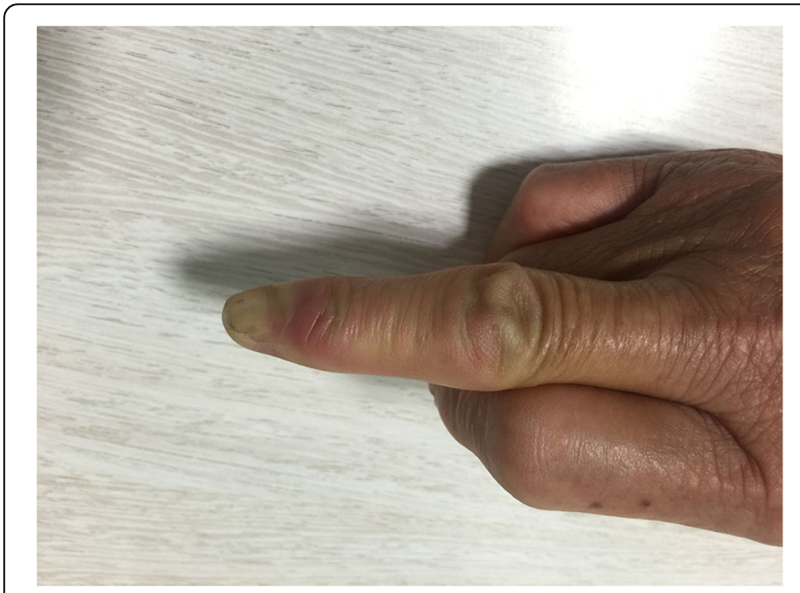

Fig. 7 The function and appearance of the affected finger are normal after surgery
In this case, MRI not only detected the tumor, it can also show the infection and the extent of edema in the affected finger.

Surgical resection is the standard treatment for glomus tumor. It is important that surgeons understand the accurate location of the tumor and the regulation of skin circulation to avoid recurrence and nail deformity $[10,11]$ or necrosis. The dilemma of this case was how to resect the tumor and in the meantime also protect the nail circulation. Based on the MRI image, we chose the lateral incision close to the radial side of the nail to solve the dilemma.

\section{Conclusion}

We have diagnosed the first case of finger infection caused by the rupture of a rare subungual glomus tumor that was initially misdiagnosed multiple times. Increased awareness of this rare tumor by both the patients and physicians may help avoid misdiagnosis and delay of early correct diagnosis and treatment of subungual glomus tumor.

\section{Abbreviation \\ MRI: Magnetic resonance imaging}

\section{Funding}

Data collection and Data analysis of this work were supported by The National Natural Science Foundation of China (grant number 81702135), Zhejiang Traditional Chinese Medicine Research Program (grant number 2016ZA124, 2017ZB057), Zhejiang Medicine and Hygiene Research Program (grant number 2016KYB101, 2015KYA100), and Zhejiang Medical Association Clinical Scientific Research Program (2013ZYC-A19, 2015ZYC-A12) fund the work.

Availability of data and materials

The dataset supporting the conclusions of this article is included within the article.

\section{Authors' contributions}

HL conceived of the study. LFC and QC participated in the design of the study. $\mathrm{HL}$ drafted the manuscript. All authors read and approved the final manuscript.

Ethics approval and consent to participate

These study protocols were approved by the Medical Ethics Committee of the First Affiliated Hospital, College of Medicine, Zhejiang University.

\section{Consent for publication}

Written informed consent for publication of her clinical details and clinical images was obtained from the patient. Upon request, a copy of the consent form is available for review by the Editor of this journal.

\section{Competing interests}

The authors declare that they have no competing interests.

\section{Publisher's Note}

Springer Nature remains neutral with regard to jurisdictional claims in published maps and institutional affiliations.

\section{Author details}

'Department of Hand Surgery, The First Affiliated Hospital, College of Medicine, Zhejiang University, \#79 Qingchun Road, Hangzhou, Zhejiang Province, People's Republic of China 310003. '2Department of Hand Surgery, Zhejiang Province People's Hospital, \#158 Shang Tang Road, Hangzhou, Zhejiang province, People's Republic of China 310014. ${ }^{3}$ Department of 
Medical Engineering, The First Affiliated Hospital, Zhejiang University, \#79 Qingchun Road, Hangzhou, Zhejiang Province, People's Republic of China 310003 .

Received: 22 August 2017 Accepted: 16 April 2018

Published online: 02 May 2018

\section{References}

1. Schiefer TK, Parker WL, Anakwenze OA, Amadio PC, Inwards CY, Spinner RJ. Extradigital glomus tumors: a 20-year experience. Mayo Clin Proc. 2006; 81(10):1337-44. https://doi.org/10.4065/81.10.1337.

2. Polman $\amalg$, De Kort GA. Glomus tumor of the finger. JBR-BTR : organe de la Societe royale belge de radiologie. 2001;84(2):73.

3. Masson P. Le Glomus neuromyo-arteriel des régions tactiles et ses tumeurs. Lyon Chirurgical. 1924:20:257-80.

4. Fujioka H, Kokubu T, Akisue T, Nagura I, Toyokawa N, Inui A, et al. Treatment of subungual glomus tumor. The Kobe journal of medical sciences. 2009; 55(1):E1-4.

5. Shin DK, Kim MS, Kim SW, Kim SH. A painful glomus tumor on the pulp of the distal phalanx. Journal of Korean Neurosurgical Society. 2010;48(2):185-7. https://doi.org/10.3340/jkns.2010.48.2.185

6. Lu H, Chen Q, Yang H, Shen H. Enchondroma in the distal phalanx of the finger: an observational study of 34 cases in a single institution. Medicine. 2016;95(38):e4966. https://doi.org/10.1097/MD.0000000000004966.

7. Fornage BD. Glomus tumors in the fingers: diagnosis with US. Radiology. 1988;167(1):183-5. https://doi.org/10.1148/radiology.167.1.2831563.

8. Schneider $\mathrm{LH}$, Bachow TB. Magnetic resonance imaging of a glomus tumor. A case report. Orthop Rev. 1991;20(3):255-6.

9. Kim DH. Glomus tumor of the finger tip and MRI appearance. The lowa orthopaedic journal. 1999;19:136-8.

10. Takata H, Ikuta Y, Ishida O, Kimori K. Treatment of subungual glomus tumour. Hand Surg. 2001;6(1):25-7.

11. Rohard I, Subotic U, Weber DM. Primary reconstruction of fingernail injuries in children with split-thickness nail bed grafts. Eur J Pediatr Surg. 2012;22(4):283-8.

Ready to submit your research? Choose BMC and benefit from:

- fast, convenient online submission

- thorough peer review by experienced researchers in your field

- rapid publication on acceptance

- support for research data, including large and complex data types

- gold Open Access which fosters wider collaboration and increased citations

- maximum visibility for your research: over $100 \mathrm{M}$ website views per year 